\title{
Mapping playgrids for learning across space, time, and scale
}

Manuscript accepted for publication in TechTrends.

\author{
Ty Hollett \\ Assistant Professor \\ The Pennsylvania State University \\ Department of Learning and Performance Systems \\ 315 Keller Building \\ University Park, PA 16802 \\ tyhollett@psu.edu \\ Remi Kalir \\ Assistant Professor \\ University of Colorado Denver \\ School of Education and Human Development \\ 1380 Lawrence St, Room 645 \\ Denver, CO 80204 \\ remi.kalir@ucdenver.edu
}




\begin{abstract}
In this article, we analyze the production of learner-generated playgrids. Playgrids are produced when learners knit together social media tools to participate across settings and scales, accomplish their goals, pursue interests, and make their learning more enjoyable and personally meaningful. Through case study methodology we examine how two platforms - Slack and Hypothesis - enabled learners to curate and participate among their own digital resources and pathways for learning. We contend that both theoretical and pedagogical development is necessary to support adult learners as they curate tools and pathways based upon their contingent needs and goals, and that the concept of playgrids does so by usefully connecting less formal social media practice with more formal professional learning across various settings and scales. In the end, we demonstrate the importance of honoring learners' desire to connect their completion of formal course activities with their less formal social media practices; both sets of practices need not be in conflict and may be complementary.
\end{abstract}




\section{Introduction}

Research on social media and learning has largely focused on individual tools (i.e.

Facebook, Twitter) and the associated capacities and practices of participatory learning (Gleason, 2015; Mazman \& Usluel, 2010). Recent studies have described how social media and practices connect learning across formal and informal settings (Greenhow \& Lewin, 2016) as learners transition from passive consumers of media to active producers of artifacts, networks, and literacies (Lankshear \& Knobel, 2011). In confronting typical notions of when and where learning occurs, we are particularly inspired by the do-it-yourself ethos that has emerged alongside social media activity, especially in terms of how learners actively design, curate, produce, and distribute with digital media in support of their own learning.

In this article, however, we are less concerned with either discrete artifacts produced by individual learners or the technical capacities of new technologies that afford such production. Rather, we emphasize how two learning environments, saturated with diverse arrangements of social media, enabled learners to knit together repertoires of tools to participate across settings and scales, accomplish their goals, pursue interests, and make their learning more enjoyable and personally meaningful. We refer to this production as a playgrid. Specifically, we define playgrids as the creative knitting together of social media tools to effectively participate across space, time, and scale. Importantly, we do not view playgrids as culminating products; rather, we view them as malleable, remixable artifacts that change shape according to one's needs over time. Furthermore, in focusing on playgrids, we shift from a focus on learning with specific social media tools to learning through social media platforms, those which "enable individuals and groups to do more with fewer resources, to innovate in ways that actually create new resources where previously there were none" (Knobel \& Lankshear, 2010, p. 17). 
Our focus on the mobilization of resources positions learners as "networked creators" who capably pursue unique trajectories of learning according to their individual needs (Hagel \& Seely Brown, 2005). Thus, in considering the role of social media in adult professional development and learning, we emphasize two platforms that enabled learners to curate - and participate among - their own digital resources and pathways for learning: Slack and Hypothesis. In our forthcoming analysis, we describe how learning through both platforms addresses Kumpulainen and Sefton-Green's (2014) observation about the need for more fluid and crosssetting learning: "A challenge for education might be to enhance boundary permeability by creating possibilities for participation, interaction, and collaboration across a diversity of sites and contexts, both within and across institutions" (p.13). To describe this form of learnergenerated curation, we offer new interpretations of professionally-relevant adult learning by illustrating the production of playgrids in two cases. Following our analysis, we contend that both theoretical and pedagogical development is necessary to support adult learners as they curate both tools and pathways based upon their needs and goals. The concept of playgrids offers a way forwarding in understanding how learners connect less formal social media practice with more formal professional learning across various settings and scales.

\section{Theoretical Perspectives}

Playgrids are inherently creative productions (Mishra, Fahnoe, \& Henrikson, 2008). For Mishra and colleagues (2008), creativity is a goal driven process of developing solutions that are novel, effective, and whole" (p. 12). Novel, effective, and whole teaching and learning solutions can provide "emergent and flexible structures for evaluating creativity" in the classroom (p. 13). We build from this foundational work on creativity, supplementing it with multi-disciplinary 
thinking related to space, time, and scale. We draw on these perspectives, in particular, as a means to spatialize creativity. That is, in this special issue on the role of social media, learning, and professional development, we work to "unbundle" the creative enterprises that educators enter into through participation in online coursework. Furthermore, by spatializing creativity, we wonder how creativity escapes the "imagined geography of learning" (Leander, Phillips, \& Taylor, 2010), or dominant expectations of when and where learning - and creativity - occurs. Thus, three complementary theoretical perspectives - on play, grids, and learning across settings - inform our spatialization of creativity through playgrids and the subsequent analysis of learning with playgrids across space, time, and scale.

First, we value notions of play and playfulness shape activity within and across varied contexts and settings. Play, according to Salen and Zimmerman (2004) may be defined as "free movement within a more rigid structure" (p. 304). We find this expansive understanding useful given that it can describe a range of participatory activities, from the mutability of learners' interests and affect in online environments (Hollett, 2016), to pre-service teacher inquiry about disciplinary concepts via mobile learning (Holden, 2016). This conceptualization of play emphasizes how the "free movement" of interest-driven and open-ended practices can occur and both by design and improvisation - through established constraints, such as the technical limitations of a tool, the requirements of a course, or the social conventions of a group.

Second, we draw upon literature about social media, distributed curation, and crisis mapping (Liu, 2014; Liu \& Palen, 2010). Crisis maps have emerged alongside social media as a response to crises (i.e. earthquakes). Individuals who produce crisis maps are known as neogeographers, or people who use and create "their own maps, on their own terms, by combining elements of an existing toolset" both local and global (Turner, 2006, p. 3). We 
suggest learners in formal course contexts can also knit together social media tools to support communal and individual practices. In this respect, we assert that playgrids emphasize ad hoc ways in which learners propel their own learning by producing networked social media arrangements in pursuit of diverse interests and objectives.

Third and finally, our notion of playgrids is informed by the ways in which individuals mobilize their learning across multiple formal and informal settings. Ecological perspectives on learning explain the ways in which individuals move across learning ecologies, or "the set of contexts found in physical or virtual spaces that provide opportunities for learning" (Barron, 2006, p. 195). These settings can include a learner's home, school, community, work, and neighborhood, as well as distributed resources such as online environments and social networks. Each of these settings is also "comprised of configurations of activities, material resources and relationships" (Barron, 2004, p. 6). By honoring the mobility and playfulness of everyday contexts for learning - alongside learners' grid-like arrangements of social media to afford such activity - we argue that playgrids demonstrate the utility of ecological perspectives when studying adult's professional learning with social media.

\section{Methods}

In this article we present two case studies (Yin, 2013). Each case details learner-produced playgrids evident in an analysis of graduate courses that featured improvisational and dynamic bundling among social media, tools, and relations. Specifically, our cases examine how adult learners curated and utilized distinctive arrangements of resources, relations, and networks to participate in both required graduate coursework and complementary interest-drive learning. Moreover, we describe how such grids supported more learning across space, time, and scale. 
It is important to note that learner-produced playgrids were neither a priori instructional objectives planned for our courses, nor were playgrids an intended unit of analysis. Rather, as designers, instructors, and researchers we noticed amidst unfolding course activity how our graduate learners knit together repertoires of tools to participate across settings and scales, accomplish their goals, pursue interests, and make their learning more enjoyable and personally meaningful. As reflective practitioners cognizant that our future course iterations will benefit from this analysis of improvisational and playful learning, we have advanced the concept of playgrids post hoc as a useful descriptive and analytical heuristic.

We arrived at playgrids through an ongoing and emergent analytic process. As instructors in our respective courses, we were always "in the middle of things" (Deleuze \& Guattari, 1997, p. 293), observing and also participating alongside graduate students as they knit together various social media tools to accomplish their goals. Analytically, we were inspired by approaches that did not treat discrete notes, comments, and interactions as "brute data" waiting to be coded (Pierre \& Jackson, 2014). Rather, we engaged in a form of post-qualitative inquiry (Pierre, 2015), informed by emergent themes that we began to witness across our respective cases over time. Our generative and reflective conversations while teaching led us to inquire about how the dominant tools that we employed - Slack and Hypothesis - enabled learners to play with their own learning across space, time, and scale. Ultimately, our research was guided by - and sought to address - the following questions:

- How do adult learners creatively navigate formal and informal social media practices via Slack and Hypothesis participation?

- How do issues of space, time, and scale inform their learning as learners navigate across these (in)formal boundaries? 
Upon the completion of the course, we revisited students' participation across media, including our respective platforms, as well as learner-produced blogs, GIFs, audio/video recordings and more. Individual messages - in chats, direct messages, and even via annotation - helped us identify analytic hot spots associated with our respective platforms and learners' experiences. That is, we questioned why learners, for instance, were excited about the technical and social possibilities afforded by channel-based collaboration (in Slack) and margin-based discussion (via Hypothesis)." These affectively charged exclamations by students led us to then further refine our understanding regarding how learners were producing their own playgrids within their courses as they knit together participation and learning opportunities across space, time, and scale.

\section{Course Context}

Our cases share important features: both were exclusively online and dedicated to the study of digital media and learning topics (i.e. game-based learning, making). Despite operating out of different universities, both courses shared many similarities, which factor into our examination of playgrids produced and leveraged by graduate learners. The online courses were intimate, with 20 students enrolled in the Slack-focused course and 13 in the course using Hypothesis. All of students were seeking a Master's Degree in an exclusively online learning technologies programs (in the Northeast and Mountain States, respectively). In both cases, a majority of learners were working professionals (i.e. K-12 and university-level educators, instructional designers, librarians, digital media creatives) and were enrolled in the program to advance their professional learning and career-specific goals. In both cases, we recognize that the playgrids produced by learners were likely a result of distinctive curricular, pedagogical, and participation features. Thus, the curation of participants' digital resources for learning varied 
between cases. This variation reflects, in part, the use of two tools - Slack in the first case and Hypothesis in the second - that created unique conditions for playgrids to seed learners' goals and interests across settings and over time.

Slack. A guiding principle for the course featured in our first case was community development among learners. Thus, Slack entered as a tool to both foster a sense of community for learners, while simultaneously offering learners a robust platform to communicate through text, video, audio, emoji, "likes" and more (Figure 1). Slack facilitates "team communication for the 21st century" (Slack, 2016). A lightweight web-based and mobile application, it enables teams (i.e. groups, classes), to organize and coordinate through chat-room-like "channels." All messages, save direct messages to individuals, are visible to all team members. Transparency and open-dialogue is valued and encouraged. More than a conversation medium, however, Slack integrates "all your tools in one place," enabling users to curate tools from across the web that will enable them to work most effectively, including Twitter, Google Hangouts, GitHub and more. Simply put, Slack allows users to pull in other platforms, as necessary, depending on their individual, or team, needs. For example, integrating Google Hangouts enables users to quickly create a Hangout by simply typing “/hangout” in their text box. Thus, Slack is a protean platform that can take on a new shape given the new needs of its users. It becomes Hangout. It becomes Twitter. Throughout the course, learners were encouraged to make Slack work for them according to their needs.

[Figure 1 here]

Figure 1. Screenshot of Slack interface, including communication among group members. 
Hypothesis. A core commitment of the course examined in our second case was close reading and extended discursive analysis of sociocultural learning theory in games and play (i.e. Gee, 2004; Peppler \& Kafai, 2010; Salen, 2008). Accordingly, significant course activity utilized Hypothesis (http://hypothes.is), an open platform for web annotation and discussion. Hypothesis is a free and open-source platform that follows a lineage of tools designed to support the annotation of online text, media, and information for discussion, collaboration, research, and learning (i.e. Glover, Xu, \& Hardaker, 2007; Rau, Chen, \& Chin, 2004). The Hypothesis browser extension allows an individual to annotate any online text-based document (i.e. webpage, PDF, blog) by highlighting text, adding comments anchored to words or passages, and by embedding media (image, videos, or GIFs) as the content of an annotation (Figure 2). Any annotation is also an invitation for discussion given a "replies" feature that structures threaded exchange among individuals.

\section{[Figure 2 here]}

Figure 2. Screenshot of PDF featuring multiple Hypothesis annotations

Annotations may be private to a user, private to a group, or visible publicly. Annotation text may also be tagged and hyperlinked. An annotation, in this respect, can serve to connect nodes in a distributed network of online resources, information, and media. Moreover, a single Hypothesis annotation may be shared (i.e. via Twitter) or embedded (i.e. in a blog post), allowing readers anywhere to access layers of discourse contributed to an ongoing conversation in the source document's margins. In this course, Hypothesis use was paired with complementary "innovative open educational practices" (Karunanayaka, Naidu, Rajendra, \& Ratnayake, 2015) primarily 
through the authorship of a public blog (http://www.gamesandlearning.wordpress.com) and a Twitter backchannel. Within this context, it was feasible to introduce open web annotation as complementary to learners' social media practices for academic and professionally-relevant learning.

\section{Playgrid Production for Professional Development Across Two Cases}

The following two cases draw upon a range of data collected over a single academic semester - including learner-produced artifacts and blogs - so as to describe emergent playgrids and associated learning practices that defined professionally-relevant adult online learning.

\section{Case 1: Playgrid Production through Slack}

In the following focus on Slack, we describe three ways in which learners produced their own playgrids throughout the course, first through their playful integration of Google Hangouts, then through the playful integration of GIFs, and finally through the playful integration of web robots (bots). In moving forward, it is important to note that these playgrids emerged as a result of learners own needs at specific moments in the course. Thus, our intention is not to focus on the tool itself (i.e. Slack, Google Hangout, etc.) but on playgrid that emerged at this moment, with this objective by learners.

Playgrid 1: Slack + Google Hangout. One of the first playgrids that emerged was that of weekly synchronous discussion through Slack + Google Hangout. By week 3, a number of groups craved further synchronous discussion with colleagues that extended beyond their regular, synchronous blog posts and in-channel group discussion. Figure three, for instance, describes one learner's message to her group prior to their regular, Tuesday-evening Hangout and another learner's response. 
[Figure 3 here]

Figure 3. learner message to other group members in anticipation of weekly Hangout.

While Slack + Google Hangout became a means to talk through readings in a more collegial setting, it also gave learners a chance to insert a unique temporal element into their own learning, especially given the flexible scheduling of the online course. In creating their own weekly hangouts, learners used available tools - capable of being integrated into Slack - to build in additional time to think, reflect, and critique their readings. In doing so, learners played with the time in which they learned, recognizing that regularly-scheduled, hour-long conversations were productive to both their learning of course material as well as to development of collegial relationships that were not bound and contained to typographic chat.

Playgrid 2: Slack + Giphy. Learners sought out other ways to move beyond textual communication with classmates, especially as a means to foster a great sense of community in this online course. In doing so, they produced another playgrid through the integration of the GIF generator, Giphy. In this playgrid-Slack + Giphy-learners supplemented their discussions with GIFs as a means to showcase their interests, emphasize points, or simply connect with others, as well as to celebrate with one another, especially after the submission of course projects (Figure 4).

[Figure 4 here]

Figure 4. Slack + Giphy to insert GIFs into discussion. 
Learners' integration of GIFs into regular communication was not trivial. Rather, they were playful, deliberate, community-building acts that enabled learners to connect with peers in ways that went beyond mere-and typical-textual description. Their integration of GIFs were acts of place-making, of fostering a dynamic sense of community that persisted from week to week. This is not to say that online courses should integrate GIF-based communication. Rather, it was learners' agency to construct their own playgrids, to integrate what they felt was necessary to produce the kind of environment within which they wanted to learn and participate, that was most important. By creating a GIF-based playgrid, learners created playful GIF-chats, similar to those which occur in other social media forums, like Tumblr. Thus, the playgrid of Slack + Giphy was, like Google-Hangout, desire-driven, a call for alternative ways to both connect with peers and respond to shared readings and writing. Importantly, the integration of GIFs into regular communication led learners to assert their forum: "It's amazing how quickly we've become a community through [Slack]."

Playgrid 3: Slack + Bots. A final playgrid produced by participants brought together Slack and automated tasks completed by web robots (bots). In particular, this course employed a bot dedicated to Really Simple Syndication (RSS). Because the course was designed in such a way that web blog posts were the primary means of reflecting on material, the Slack + RSS bot playgrid provided a more efficient means to access peers' web blogs without having to regularly visit the website itself, as the bot created a dedicated channel for links to learner blog posts to appear once they were submitted by learners (Figure 5).

[Figure 5 here]

Figure 5. Bot-produced snipped of learner blog posts. 
This implementation of RSS feeds further cemented Slack as a learning hub for learners, one in which they could customize according to their needs and desires. learners could further customize their feed channel, incorporating, for instance, feeds from other scholars, communities, or organizations.

Another bot, called Slack Digest, added a further layer of customization as it provided summaries of discussion topics each week. Because of the sheer amount of text, links, and videos that learners shared throughout a given week, a desire emerged to be able to quickly synthesize major topics. The Slack Digest bot, in turn, sent out weekly direct messages to subscribers highlighting major topics of conversation as well as curating all links shared that week (Figure $6)$.

[Figure 6 here]

Figure 6. Example of message send to individuals through Slack Digest bot, including summary of conversation and all links shared that week.

For instance, Figure 6 illustrates a brief snippet of conversation that resulted from a learner sharing a link. Another learner entered the conversation by sharing a link to a website herself and further conversation ensued. Furthermore, Slack digest then grabbed all links shared throughout the week and organized them below.

Again, we are not necessarily concerned here with the integration of bots in learning settings. Rather, we are interested in how learners continually sought to customize their learning experience, how they recognized their own needs over time--like the vast amount of text they 
were generating as a class and the need to effectively sift through it--seeking out the appropriate tools that could best help them. Slack + bots, then, became a means to consolidate all of the "movement" that online learning can demand (accessing blogs, viewing videos, reading articles, etc.) as well as to curate the rich, related content that peers were regularly sharing and discussing with one another.

\section{Case 2: Playgrid Production through Hypothesis}

Like our previous emphasis on Slack, this case does not examine Hypothesis annotations as discrete and disconnected learning artifacts. Rather, we consider the multimodal and networked qualities of annotation - as a social and collaborative practice among learners - that became consequential to the curation and use of playgrids. Specifically, we describe playgrids associated with Hypothesis and annotation across platforms, annotation as blog commentary, and the improvisational dynamics of an annotation flash mob.

Playgrid 1: Hypothesis and Annotation Across Platforms. One example of a Hypothesis playgrid knit together course readings, distributed resources, and online media. The practices of web annotation traveled with learners as they engaged with PDFs hosted on the course blog, transformed websites sharing news and opinion into their own conversational forums, and gathered together complementary media and resources as annotation content. One example of such activity occurred during the third cycle of readings when two learners facilitated an annotation discussion as a cross-setting "Easter egg" hunt (an "Easter egg" is an intentional inside joke or hidden message, often employed in video games). Announced via Twitter, the learners authored a series of annotations - among dozens added to five course readings - that served as "clues" for their hidden message. The content of these annotation clues combined 
academic content (such as a hyperlinked resource about social constructivism) with usergenerated media as playful visual metaphors (Figure 7).

[Figure 7 here]

Figure 7. Composite image of Twitter, Hypothesis, and digital media activity connecting academic content with "Easter egg" hunt

In this instance, the emergent playgrid consisted of a social network (Twitter), online documents (the reading PDF and linked academic website), and a media sharing platform (Flickr), all of which were connected through the creative use of Hypothesis web annotation. This playgrid set a precedent for learners' subsequent circulations of activity among social networking, web annotation, and digital media creation.

Playgrid 2: Hypothesis Annotation as Blog Commentary. A second playgrid mediated by Hypothesis connected web annotation with blogging practices by both complementing and subverting the established conventions of that platform. Learners in this course wrote multiple blog posts during a typical two-week cycle; posts reviewed literature, some analyzed game play experiences, and yet others offered metacognitive reflections about individual learning in the course. While the graduate program required learners to author a public blog, the specific blog service and individual blog settings were not specified. Accordingly, learners were authoring across a variety of blogging platforms (i.e. Wordpress, Blogger, Weebly), and with a range of settings for comment moderation. Web annotation, however, afforded learners multiple creative opportunities as both blog authors and commenters. When posting media, authors often included text-based introductions to encourage peer commentary via annotation. In other cases, and in 
response to more conventional blog comments, some authors provided their subsequent replies as web annotations (Figure 8).

[Figure 8 here]

Figure 8. Composite image of blog posts inviting web annotation as comments and featuring web annotation of blog comments

As these brief examples indicate, learners' blogging practices - such as a post's structure and content, as well as the interactions of commentary - were progressively influenced by the technical and social conventions of web annotation. A cross-setting playgrid emerged which utilized the features of Hypothesis to meet the contingent needs of peer feedback and conversation among varied blogging platforms.

Playgrid 3: Hypothesis and an Annotation Flash Mob. Finally, Hypothesis served as a means for experimental and improvisational conversation beyond assignment requirements and in collaboration with individuals not formally enrolled in the course. Whereas most web annotation was asynchronous among coursemates, a learner-initiated opportunity arose toward the end of the semester for a synchronous annotation flash mob. A public invitation was announced via Twitter and blog post for interested individuals to gather at an online location (i.e. the URL of an article about online education) at a designated time and collectively annotate in real time. The playgrid which emerged during this synchronous web annotation was created by over two dozen individuals as an ad hoc community, only 7 of whom were course participants. Contributing to such social reading and writing in real time allowed participants to simultaneously: Utilize Hypothesis to annotate in the margins of the designated article; promote 
and respond to tweets about the flash mob via Twitter; read notifications about annotations sent via email; access a live stream of Hypothesis annotations and respond to threaded exchanges; and curate related resources - such as other media and texts - via hyperlink within layered annotation.

This emergent playgrid brought together both K-12 and higher education practitioners, learners from formal course contexts with individuals whose learning was more informal, and participants with a wide range of open annotation experiences. By knitting together these varied contexts and practices, the synchronous annotation of this flash mob created playful opportunities for shared activity. As one learner noted via annotation to a blog post that summarized the event, "I had tweeted that I was in lurker mode prior to the flash mob, but once I stepped into the sandbox, I couldn't help but participate." Another learner's reflection about the use of web annotation resonated with both the flash mob dynamics and, more generally, the critical role of web annotation to support learning with and through playgrids: "Annotation via Hypothesis this semester was one of the greatest challenges and greatest rewards.... the peer interactions and inquiry changed the way I looked at discovering critical concepts in course literature... the experience ultimately changed the way I imagined theory, literature, and peer interaction as it comes together."

\section{Discussion}

Playgrids, we have demonstrated, are contingent arrangements of distributed online resources that enabled learners to accomplish their goals, pursue interests, and make learning more enjoyable and meaningful. In this discussion, we consider how salient qualities of adult learning via playgrids - such as participation in shared activity across space, time, and scale - are important for designers and educators to consider as new forms of professional development 
opportunities are afforded by social media practices. In doing so, we recognize that challenging questions arise concerning the use of social media to support adult learning as relevant to professional needs and interests. For example, how might designers and educators create the conditions - both within a course and across an academic program - that proactively encourage learners to curate and leverage their own playgrids? And how, as learning activities progress, might educators and professional development facilitators synthesize the structure of established objectives with the emergent participation patterns that cultivate playgrids?

As designers and educators, we suggest that it is possible to create the conditions for emergent playgrids by recognizing that the affordances and constraints of all tools reflect particular ideologies (i.e. Morria \& Stommel, 2014; Watters, 2016). In both of our cases, we largely (or entirely) eschewed traditional learning management systems (LMS), as such platforms are frequently ensconced from everyday online activities and social media, prescriptive in delineating what counts as pedagogy, and rigid in measuring - much less honoring! expressions of student learning. Neither Slack nor Hypothesis were designed explicitly for use in formal education contexts. However, that is precisely what attracted us to these platforms; both were easily bundled with other social media to enhance cross-setting learning, both propelled activity from the so-called local (i.e. single graduate course) to the so-called global (i.e. networks of blogs and Twitter), and both offered free services that learners might very well use after the course concluded. Rather than segregate adult learners from their ongoing and everyday use of social media by requiring formal learning within the "secret garden" of a LMS, we contend that our cases might encourage adult learning designers and practitioners to consider the advantages of utilizing tools with low barriers for participation, more equitable interaction, and the amplification of interest and personal meaning. 
Moreover, we both learned alongside our students. Advocating and practicing an experimental ethos helped create learning conditions within which playgrids could be developed and deployed. While we had each, respectively, used Slack and Hypothesis more informally and outside of course contexts, neither of us had taught with either platform before. This pedagogical decision contradicts conventional wisdom that suggests educators must be capably trained to effectively use learning technologies in high-stakes contexts, like graduate education (consider, for example, routine LMS trainings at the beginning of each semester which reinforce norms that may actually curtail instructor agency). Because our repertoires of practice were developing transparently, our learners received an explicit message about encouraging collective experimentation and discovery. This distributed approach to knowledge construction had the effect of magnifying learners' agency. For example, graduate students exercised greater control over the temporality of their learning, creating professional development pockets for themselves that operated outside the constraints of course schedules. They also appropriated digital and online contexts - and at private, socially intimate, and public levels of participation - to accomplish required learning objectives, pursue their own interests, and foster creative expression. We suggest our cases challenge a delivery model of technical skills acquisition too frequently practiced in adult professional learning. On the contrary, for participatory social media to (further) transform adult professional learning, opportunities should be designed and embraced whereby learners can experiment without fear of failure, and educators can publicly learn alongside their students.

\section{Conclusion}

In this article we have presented two cases that illustrate how adult learners knit together - across space, time, and scale - various resources and relations to accomplish their goals, pursue 
their interests, and make their learning more enjoyable and meaningful. Playgrids, we suggest, may help designers, educators, and researchers dislodge themselves from sedimented views about how, where, and when professionally-relevant learning can - and should - occur.

Furthermore, we believe playgrids are a useful heuristic indicating a need for more emergent and expansive professional development that better aligns with the rhythms and repertoires of learning in a digital era (Campbell, 2016). Our cases have identified initial "knowledge of practice" (Cochran-Smith \& Lytle, 1999) about design and pedagogy that we anticipate will be useful for others committed to honoring the improvisational and playful relations between social media and professionally-relevant learning.

We have demonstrated that it is important to honor learners' desire to connect their completion of formal course activities with their less formal social media practices; both sets of practices need not be in conflict and may be complementary. We also know that not every artifact (i.e. a Slack message, a Hypothesis annotation) or arrangement of resources (i.e. Slack and Google Hangouts, Hypothesis and blogging) needs to be formally evaluated. A welldesigned course will present ample opportunity for assessment, and activity associated with playgrids can be appreciated as formative evidence of interest-driven learning, and need not be co-opted by instructors as a summative means of evaluation. Finally, the playful use of social media oftens propels public engagement beyond the seemingly codified boundaries of formal learning (i.e. the annotation flash mob). By embracing such public-facing learning opportunities, we know it is important to open up our pedagogy and commit to a teaching practice that is more transparent and participatory.

Graduate courses can be designed to support adult learners as they curate tools and pathways based upon their contingent needs and goals. The creative and experimental 
development of learners' playgrids did not detract from our ability - as either designers or instructors - to foster deep engagement with established learning objectives. Both of our cases demonstrate a productive tension between the structure of a priori objectives (primarily with course content) and the emergent patterns of participation that cultivated how learning was meaningfully accomplished via playgrids. Not only can playgrids be established to help connect less formal social practice with more formal course activity, we argue that playgrids are important given increasing participation with open tools and pedagogy in higher education. As such, designers and educators should enable learners' knitting-together of tools in a grid-like fashion so more playful and project-specific learning can span space, time, and scale.

\section{Compliance with Ethical Standards}

This research received no specific grant from any funding agency in the public, commercial, or not-for-profit sectors.

\section{Ethical Approval}

All procedures performed in studies involving human participants were in accordance with the ethical standards of the institutional and/or national research committee and with the 1964 Helsinki declaration and its later amendments or comparable ethical standards.

This article does not contain any studies with animals performed by any of the authors. 


\section{Informed Consent}

Informed consent was obtained from all individual participants included in the study. 


\section{References}

Alfrink, K. (2014). The gameful city. In S. Walz \& S. Deterding (Eds.), The Gameful World: Approaches, Issues, Applications (pp. 527-560). Cambridge, MA: The MIT Press.

Barron, B. (2004). Learning ecologies for technological fluency: Gender and experience differences. Journal Educational Computing Research, 31(1), 1-36.

Barron, B. (2006). Interest and self-sustained learning as catalysts of development: A learning ecologies perspective. Human Development, 49(4), 193-224.

Bogost, I. (2007). Persuasive games: The expressive power of videogames. Cambridge, MA: The MIT Press.

Campbell, G. (2016). Networked learning as experiential learning. EDUCAUSE Review, 51(1), 70-71.

Cochran-Smith, M., \& Lytle, S. L. (1999). Relationships of knowledge and practice: Teacher learning in communities. Review of research in education, 24, 249-305.

Deleuze, G., \& Guattari, F. (1988). A thousand plateaus: Capitalism and schizophrenia. Bloomsbury Publishing.

Gee, J. (2004). Situated language and learning: A critique of traditional schooling. New York, NY: Routledge.

Gleason, B. (2015). New literacies practices of teenage Twitter users. Learning, Media and Technology, 1-24.

Glover, I., Xu, Z., \& Hardaker, G. (2007). Online annotation-Research and practices. Computers \& Education, 49(4), 1308-1320. 
Greenhow, C., \& Lewin, C. (2016). Social media and education: Reconceptualizing the boundaries of formal and informal learning. Learning, Media and Technology, 41(1), 6-30.

Hagel III, J., \& Brown, J. S. (2011). From push to pull: Emerging models for mobilizing resources. Journal of Service Science (JSS), 1(1), 93-110.

Holden, J. I. (2016). Mobile inquiry-as-play in mathematics teacher education. On the Horizon, 24(1), 71-81.

Hollett, T. (2016). Interests-in-motion in an informal, media-rich learning setting. Digital Culture \& Education, 8(1).

Karunanayaka, S. P., Naidu, S., Rajendra, J. C. N., \& Ratnayake, H. U. W. (2015). From OER to OEP: shifting practitioner perspectives and practices with innovative learning experience design. Open Praxis, 7(4), 339.

Knobel, M., \& Lankshear, C. (2010). DIY media: Creating, sharing and learning with new technologies. New York: Peter Lang.

Kumpulainen, K. \& Sefton-Green, J. (2014). What is connected learning and how to research it? International Journal of Learning and Media, 4(2), 7-18.

Lankshear, C., \& Knobel, M. (2011). New literacies. New York, NY: McGraw-Hill Education.

Leander, K.M., Phillips, N.C., \& Taylor, K.H. (2010). The changing social spaces of learning: Mapping new mobilities. Review of Research in Education, 34(1), 329- 394. 
Liu, S. B. (2014). Crisis crowdsourcing framework: designing strategic configurations of crowdsourcing for the emergency management domain. Computer Supported Cooperative Work (CSCW), 23(4-6), 389-443.

Liu, S. B., \& Palen, L. (2010). The new cartographers: Crisis map mashups and the emergence of neogeographic practice. Cartography and Geographic Information Science, 37(1), 69-90.

Mazman, S. G., \& Usluel, Y. K. (2010). Modeling educational usage of Facebook. Computers \& Education, 55(2), 444-453.

Mishra, P., Fahnoe, C., \& Henriksen, D. (2013). Creativity, self-directed learning and the architecture of technology rich environments. TechTrends,57(1), 10.

Morris, S. M., \& Stommel, J. (2014). If Freire made a MOOC: Open education as resistance. Hybrid Pedagogy: A Digital Journal of Learning, Teaching, and Technology. Retrieved from http://www .digitalpedagogylab.com/hybridped/freire-made-mooc-open-educationresistance/

Peppler, K., \& Kafai, Y. (2010). Gaming fluencies: Pathways into participatory culture in a community design studio. International Journal of Learning and Media, 1(4), 45-58.

Pierre, E. A. S., \& Jackson, A. Y. (2014). Qualitative data analysis after coding. Qualitative Inquiry, 20(6), 715-719.

Pierre, E. A. S. (2012). Post qualitative research. Collecting and Interpreting Qualitative Materials In Denzin, N. K., \& Lincoln, Y. S. (Eds.). Collecting and interpreting qualitative materials (Vol. 3). London, UK: Sage. 
Rau, P. L. P., Chen, S. H., \& Chin, Y. T. (2004). Developing web annotation tools for learners and instructors. Interacting with Computers, 16(2), 163-181.

Salen, K. (Ed.). (2008). The ecology of games: Connecting youth, games, and learning. Cambridge, MA: The MIT Press.

Salen, K. \& Zimmerman, E. (2004). Rules of play: Game design fundamentals. Cambridge, MA: MIT Press.

Slack (2016). Slack. Retrieved from www.slack.com

Turner, A.J. (2006). Introduction to neogeography. Cabastopol, California: O'Reilly Media Inc.

Watters, A. (2016, April 14). The ideology of the blockchain (for education). Retrieved from http://hackeducation.com/2016/04/14/blockchain-ideology

Yin, R. K. (2013). Case study research: Design and methods. London, UK: Sage. 